\title{
APROXIMAÇÃO À SUBJ ETIVIDADE DE ENFERMEIROS COM A VIDA: AFETIVIDADE E SATISFAÇÃO EM FOCO
}

\author{
Approach on nurses' subjectivity with life: focused on affection and satisfaction \\ Acercamiento a la subj etividad de enfermeros con la vida: enfoque en la afectividad y \\ satisfacción
}

Selda Gomes de Sousa Alves ${ }^{1}$

Tarciana Sampaio Costa ${ }^{4}$

\author{
Tatiana Cristina Vasconcelos ${ }^{2}$ \\ Maura Vanessa Silva Sobreira ${ }^{5}$
}

Francisco Arnoldo Nunes de Miranda ${ }^{3}$

\section{RESUMO}

Objetivou-se analisar aspectos da subjetividade de enfermeiros por meio de indicadores de afetividade e satisfação com a vida. Estudo exploratório descritivo, de abordagem quantitativa. Participaram 20 enfermeiros atuantes na Estratégia de Saúde da Saúde, do município de Sousa, PB, Brasil, que responderam ao Questionário de Saúde Geral (QSG-12). Os principais resultados indicaram que os enfermeiros apresentaram média de 5,73 de Afetos Positivos e 1,86 de Afetos Negativos. A média de satisfação com a vida foi de 4,03. Inferiu-se que os enfermeiros apresentaram nível satisfatório de saúde. Contudo, este resultado não deve negar a necessidade de cuidados permanentes por parte dos enfermeiros em relação à sua saúde, uma vez que o cuidado implica o desempenho profissional. Assim, a habilidade de cuidar de si deve ser adquirida e aprimorada desde a formação.

Palavras-chave: Qualidade de Vida. Satisfação Pessoal. Afeto. Enfermeiro. Promoção da Saúde.

\section{Abstract}

It was aimed to analyze aspects of nurses' subjectivity, through indicators of affection and satisfaction with life. This is an exploratory descriptive study of quantitative approach. Twenty nurses working in Family Health Strategy, of the municipal district of Sousa, PB, Brazil, participated in the study and answered to the General Health Questionnaire (QSG-12). The main results indicated that nurses presented average of 5.73 of Positive Affections and 1.86 of Negative Affections. The life satisfaction average was of 4.03 . It was concluded that nurses presented satisfactory health level. However, this result should not deny the need for permanent cares of nurses concerning their health, once the care reflects in the professional performance. Thus, the ability of taking care of themselves should be acquired and improved from the formation.

Keywords: Quality of life. Personal satisfaction. Affect. Nursing. Health promotion.

\section{Resumen}

Este estudio tuvo el objetivo de analizar aspectos de subjetividad de enfermeros, a través de indicadores de afecto y satisfacción con la vida. Estudio exploratorio de enfoque cuantitativo. Participaron veinte enfermeros de la Estrategia de Salud Familiar, del municipio de Sousa, Paraíba, Brasil, que respondieron al Cuestionario de Salud General (GHQ-12). Los principales resultados indicaron que los enfermeros tenían una media de Afectos Positivos de 5,73 y 1,86 de Afectos Negativos. La media de satisfacción con la vida fue de 4,03. Se concluyó que los enfermeros tenían un nivel satisfactorio de salud. Sin embargo, este resultado no debe negar la necesidad de atención permanente por parte del enfermero con respecto a su salud, ya que eso requiere en el desempeño del trabajo cuidadoso. Por lo tanto, la capacidad de cuidarse a sí mismos debe ser aprendida y mejorada desde la formación.

Palabras clave: Calidad de vida. Satisfacción personal. Afecto. Enfermería. Promoción de la salud.

\footnotetext{
'Doutoranda em Saúde Pública pela (CPqAM/FIOCRUZ)- Recife- PE. Brasil. Email: selda.gomes@hotmail.com ;'Doutoranda em Educação pela Universidade Estadual do Rio de Janeiro. Docente da Universidade Estadual da Paraíba. Brasil. Email: vasconcelostc@yahoo.com.br; ${ }^{3}$ Doutor em Psiquiatria pela

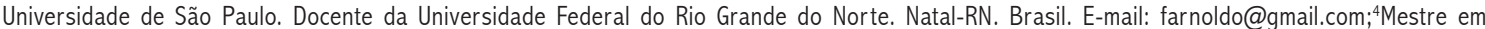
Enfermagem pela Universidade Federal do Rio Grande do Norte. Docente das Faculdades Integradas de Patos. Brasil. Patos-PB. E-mail: tarcianasampaio@yahoo.com.br; ${ }^{5}$ Professora Mestre Assistente II da Universidade Estadual do Rio Grande do Norte. Natal - RN. Brasil. E-mail: maurasobreira@yahoo.com.br
} 


\section{Aproximação à subjetividade de enfermeiros}

\section{INTRODUÇÃO}

A enfermagem, desde o seu surgimento, passou por várias transformações em sua prática, que ocorreram devido às influências históricas, sociais e culturais. Nesta perspectiva, urgiu-se a necessidade de estudos relacionados à prática de enfermagem no âmbito da subjetividade e da afetividade, ambos imbricados no processo de cuidar, uma vez que esta prática circunscreve diversos sentimentos, emoções, atitudes e valores.

Conhecer e reconhecer a subjetividade torna-se essencial para o desenvolvimento da enfermagem no processo de cuidar humanizado, quer na dimensão instrumental, quer na expressiva. A dimensão instrumental do cuidado caracterizase por ações físicas desempenhadas e relacionadas a papéis que cumprem expectativas sociais inscritas nos processos de cuidar, permeados por saberes e fazeres inscritos no seu estatuto societário. Já a dimensão expressiva do cuidado em enfermagem caracteriza-se pela natureza emocional, resultando em interações que permitem o ser humano expressar seus sentimentos relacionados à experiência ou à vivência no processo saúde-doença, incluindo a intuição e expressão da subjetividade. ${ }^{1}$

Cuidar de um ser humano não é uma atividade simples, isto porque cada ser é único em sua essência e da particularidade vivida em situações que o tornam vulneráveis, tais como as situações de desequilíbrio, físico e/ou mental. Portanto, o cuidado de enfermagem, paradoxalmente, sempre se faz na dimensão da complexidade, multiplicidade e singularidade. Outrossim, não existe sequer um cuidado de enfermagem neutro, mas multidimensional.

Sabe-se que, na maioria das vezes, uma única palavra durante um atendimento representa um efeito devastador sobre o paciente, com recíproca verdadeira. Sendo assim, a relação entre a equipe de enfermagem e o paciente, na perspectiva da intersubjetividade, ao se desenrolar em situações de vulnerabilidade, expõe tanto quem cuida quanto quem é cuidado a uma gama de emoções e expectativas que entremeiam a competência e o profissionalismo deste profissional.

Destarte, o trabalho em saúde impõe aos profissionais enfermeiros uma concepção psicodinâmica da afetividade e da subjetividade, acarretando, a mais das vezes, instabilidade física e emocional. A rotina circunscreve um alto grau de tensão e conflito que perpassa toda a equipe, resultante das inúmeras situações desencadeadas pelo processo de trabalho, favorecendo efeitos ansiogênicos diante das demandas.

Torna-se claramente percebida em situações limítrofes, localizadas na interface da atuação propriamente dita, ou seja, na convivência diária a partir do fluxo de inúmeras pessoas transitando e conversando, sons agudos, intermitentes e variados, queixas constantes, ansiedade, tristeza, dor, morte e longas jornadas de trabalho, no cotidiano da maioria dos profissionais enfermeiros, o que conduz a reflexões sobre seu próprio ser. ${ }^{2}$
0 cuidado convertido em nuclear em uma profissão abandona a execução pela afetividade expressiva e espontânea, seja na forma carinhosa ou agressiva, como observado em ambiente doméstico. 0 trabalhador de enfermagem tem sido preparado para auxiliar na recuperação do doente ou para assisti-lo em sua dor. A dimensão trabalhista requer que 0 cuidado prestado seja remunerado e que encerre um agir científico, terapêutico e de qualidade.

Assim, faz-se necessário, além de ser consumidor de pesquisa, do domínio das técnicas e tecnologias, ser guardião e mantedor da saúde, e ainda mediá-la por afetividade, sem que a expressão deste afeto seja uma representação necessária, pois um dos códigos internalizados pela enfermagem advém da ética utilitarista, em que se exige a devoção e generosidade em relação ao paciente. ${ }^{3}$

A contaminante leitura de artigos publicados também remete a três outras reflexões sobre a prática na arte e na ciência da Enfermagem e sua plasticidade.

A primeira diz respeito à possibilidade terapêutica, tecnológica ou medicamentosa de um usuário dispor; entretanto, jamais Ihe faltará a possibilidade terapêutica de cuidados de enfermagem - nem mesmo depois da morte, porque se cuida do seu corpo e de sua família.

A segunda deriva do conceito de alta complexidade de cuidado pela enfermagem - um usuário pode estar em uma unidade de terapia intensiva, com sua estabilidade hemodinâmica dependente do aparato tecnológico, ou em sua residência na comunidade ou em visita ao ambulatório de especialidades de um hospital, com sua estabilidade hemodinâmica frágil ou comprometida por aspectos socioeconômicos, educacionais ou ambientais. A terceira deriva do conceito de que investigações em saúde física e mental em contextos institucionais e comunitários precisam ser disseminadas e ter retorno social em curto prazo, diminuindo a distância entre o avançar da ciência e o usufruir dos resultados desse avanço pela população. ${ }^{4}$

Diante de tais considerações, percebeu-se o quanto é abrangente o trabalho em enfermagem, surgindo a necessidade de estudar questões relacionadas ao "Ser-enfermeiro". Para tanto, o estudo objetivou analisar aspectos da subjetividade de enfermeiros por meio de indicadores de afetividade e satisfação com a vida profissional.

\section{REVISÃO DA LITERATURA}

Há evidências de que a ocorrência de determinados fatos na vida de uma pessoa pode acarretar mudanças no estado de saúde que dizem respeito não tão somente às situações extremas, tal como a violência urbana, mas à vivência de fatos não tão dramáticos e extremos que se inscrevem na rotina do dia a dia com reflexo na sua afetividade e subjetividade.

A vida afetiva, por ser uma dimensão psíquica, dá cor, brilho e calor a todas as vivencias humanas. Sem 
afetividade, a vida mental torna-se vazia, sem sabor e ocorre sempre em um contexto de relação do eu com 0 mundo e com as pessoas, variando de um momento para outro na medida em que os eventos e as circunstâncias da vida se sucedem. ${ }^{5}$

0 termo afetividade por ser genérico, compreende várias modalidades de vivências afetivas, como o humor ou estado de ânimo, as emoções, os sentimentos, os afetos e as paixões. A afetividade caracteriza-se particularmente por sua dimensão de reatividade, ou seja, reação afetiva de um indivíduo, através da sintonização afetiva ou irradiação afetiva. $^{5}$

A sintonização afetiva diz respeito à capacidade da pessoa de sintonizar-se com o meio ambiente, ou seja, de ser influenciado afetivamente por estímulos externos, podendo entristecer-se diante de ocorrências dolorosas e alegrar-se com eventos positivos. A irradiação afetiva é a capacidade que a pessoa tem de transmitir, irradiar ou contaminar os outros com o seu estado afetivo momentâneo, estimulando os outros a sintonizarem com ele. ${ }^{5}$

$\mathrm{Na}$ prática, a subjetividade está relacionada à individualidade de cada ser. Assim, no processo de cuidar satisfatório e adequado, o enfermeiro deve estar bem interiormente, ou seja, com seus sentimentos em equilíbrio, uma vez que cada palavra proferida possui grande repercussão no tratamento, estando expostos à repercussão tanto quem é cuidado quanto o próprio cuidador, influenciando na qualidade do seu trabalho e no reconhecimento enquanto profissional.

0 cuidar em enfermagem é considerado complexo, pois envolve sentimentos expressos tanto pelo enfermeiro quanto pelo paciente; sendo assim, não há cuidado de enfermagem simples. Nestes termos, a arte de cuidar quanto aos cuidados prestados pela profissão, com significados tangíveis ao encontro de enfermeiros com os clientes, é um aspecto complicado na questão de formar enfermeiros, pois é um aspecto que se implica, intrínseca e intrinsecamente, na intimidade do ato de conhecer, e consequentemente, no sentido da enfermagem como profissão. $^{6}$

0 cuidar tem um significado amplo, inserido na assistência, representa mais que um momento de atenção, mas uma atitude de preocupação, ocupação, responsabilização e envolvimento afetivo com o ser cuidado. ${ }^{2,7-8}$

0 verbo cuidar em português significa atenção, cautela, desvelo, zelo. Assume ainda características de sinônimo de palavras como imaginar, meditar, empregar atenção ou prevenir-se. Como uma atitude e característica primeira do humano, se desconsiderada, acaba por prejudicar a si mesmo e por destruir o que estiver a sua volta. Nesse contexto, os profissionais enfermeiros, ao estar com o outro, passam a cuidar, participar das buscas, dos sofrimentos e sucessos. 0 cuidado por sua própria natureza possui dois significados que se interrelacionam, por ser uma atitude de atenção e solicitude para com o outro, ao mesmo tempo em que representa preocupação e inquietação, pois o cuidador se sente envolvido afetivamente e ligado ao outro.?

Dessa forma, faz-se necessária a instrumentalização com ênfase no emocional do profissional, que, por sua peculiaridade no processo de cuidar, invariavelmente irá se expor e se colocar como ferramenta de trabalho. Some-se neste processo a disponibilidade do enfermeiro para entender e lidar com a "pessoa inteira" ao se colocar diante da sua própria existência. ${ }^{9}$

A história do cuidado humano e da Enfermagem como ciência tem uma conexão fortemente ancorada no valor humano; no entanto, o foco da atenção sempre esteve mais voltado para o cuidado do outro, do ser doente. Todavia, recentemente foi redirecionado o cuidador. Assim, questionou-se: quem garante ao enfermeiro, em seu trabalho, o alívio do sofrimento e da manutenção da dignidade em meio às experiências de vida e de morte?

0 legado nightingaliano, sem dúvidas, se faz presente na formação profissional, marcadamente acentuado pela dualidade. De um lado, acentua-se a disciplina, o autoritarismo e a organização; por outro, exige-se obediência, servilismo e, docilidade. ${ }^{8}$ As duas características possuem algo em comum, em maior ou menor intensidade, ou seja, são cercadas pela abnegação do eu, pela renúncia dos sentimentos e da vontade própria. De igual forma, o processo de formação do enfermeiro guiou-se por essas características, sendo construída em base da excelência pela técnica, fundamentada no modelo biológico de assistência à saúde, sem que fosse dada a mesma importância para os processos relacionais. ${ }^{9}$

Contemporaneamente, outro design delineou-se ao papel tradicional do enfermeiro ao ressaltar e resumir como loci do fazer enfermagem, centrado no cuidado, ressignificando nas discussões a partir das práticas e dos saberes decorrentes da ampliação da esfera de atuação, albergando ao processo de cuidar aqueles referentes ao cuidador, além do comprometimento político com a responsabilidade e do compromisso social.

Emerge, portanto, a importância do investimento no desenvolvimento pessoal do enfermeiro ao sinalizar aspectos relevantes e necessários a esse processo através da implantação dos planos de desenvolvimento profissional e pessoal, do for talecimento das relações interpessoais no trabalho e dos programas específicos de promoção e prevenção da saúde física e mental dos mesmos. ${ }^{9}$

Registra-se, nos últimos anos, um aumento substancial de pessoas queixosas de sinais e sintomas caracterizados e indicativos daqueles circunscritos às doenças mentais, dos quais se destacam a ansiedade e a depressão como nexo causal às condiç̧̃̃es dos processos de trabalho. Não obstante, confundem-se com problemas orgânicos, sendo tratados erroneamente por ser a dor da 


\section{Aproximação à subjetividade de enfermeiros}

subjetividade a qual é apreendida a partir das observações comportamentais e das queixas encaminhadas ao consultório pelo paciente. De modo geral, estas são pouco precisas e difusas, pois dizem respeito tanto aos fatores físicos como psíquicos da saúde, por ser uma característica subjetiva da expressão humana. ${ }^{10}$

Sabe-se que distúrbios mentais, apresentados em algum momento da vida, interferem no trabalho ou nas atividades do cotidiano. Neste sentido, nos serviços de saúde, a maioria do contingente profissional centra-se na equipe de enfermagem, por ser a que mais dedica tempo aos pacientes, agregando valor ao resultado final da organização.

Concorda-se que investigar sentimentos, necessidades e desejos deste grupo constitui-se em uma abrangente fonte de dados que pode fornecer aos serviços de saúde pistas e indicações para as ações básicas e capacidade de serem implementadas, visando a uma assistência satisfatória.

A internação é um momento bastante delicado na vida do doente, pois este se encontra fragilizado, desprotegido e necessita de atenção. Se esta equipe não estiver adequadamente feliz e satisfeita com sua atividade profissional, dificilmente haverá profissionais atendendo adequadamente a esta população. ${ }^{11}$

Desse entendimento, considera-se a satisfação no trabalho como um dos indicadores de Qualidade de Vida no Trabalho, e sua medida tem sido utilizada em estudos no Brasil e no exterior. ${ }^{7-9}$

\section{MÉTODO}

Trata-se de um estudo exploratório descritivo, de abordagem quantitativa. Adotaram-se as contribuições da psicometria, cujos instrumentos de avaliação psicológica têm sido deveras utilizados.

Para coleta dos dados, utilizou-se um instrumento autoaplicável denominado Questionário de Saúde Geral (QSG) com 12 itens capazes de detectar doenças psiquiátricas não severas, ou seja, não psicóticas. Este instrumento apresenta como vantagem o baixo custo operacional e o uso de materiais, pois sua utilização requer apenas lápis e papel para execução, sem comprometimento da confiabilidade, além de garantir bem-estar psicológico, principalmente em estudos ocupacionais. ${ }^{12}$ Adicionalmente, neste estudo, optou-se pelos indicadores de afetividade e satisfação com a vida. ${ }^{13}$ Ressalte-se que, embora distintos, enquanto instrumentos de apreensão dos dados, situamse complementarmente ao objetivo deste estudo.

0 questionário sociodemográfico caracteriza os sujeitos com relação à idade, ao sexo, à classe social, ao estado civil e ao tempo de atuação profissional.
A Escala de Afetos Positivos e Negativos de Diener e Emmons avalia os afetos através de 10 adjetivos, sendo cinco positivos e cinco negativos. ${ }^{14}$ Exemplificando: alegre, satisfeito, divertido, deprimido, preocupado, raivoso. Este instrumento avalia o quanto o participante tem experimentado cada uma destas emoções nos últimos dias, e é respondido em uma escala de sete pontos, com os extremos 1 (Nada) e 7 (Extremamente).

A Escala de Satisfação com a vida de Ed Diener comprova a adequação dos seus parâmetros psicométricos. É composta por cinco itens, respondidos em uma escala tipo Likert, variando de 1 (Discordo Totalmente) a 7 (Concordo Totalmente). Exemplificando: estou satisfeito com minha vida e as condições da minha vida são excelentes.

0 Município de Sousa conta com 26 enfermeiros, distribuídos em unidades básicas de saúde. Destes, 24 foram convidados a participar da pesquisa, uma vez que os outros dois encontravam-se de férias. Mediante o aceite, solicitou-se a assinatura do Termo de Consentimento Livre Esclarecido, bem como o preenchimento do questionário sociodemográfico, da Escala de Afetos Positivos e Negativos e da Escala de Satisfação com a Vida, aos primeiros 20 dias de junho de 2008, os quais foram entregues em mãos pela pesquisadora responsável nos respectivos endereços de trabalho e recolhidos nos locais, data e horários previamente agendados. Dentre os 24 questionários distribuídos, houve o retorno de 20 , sendo estes os sujeitos deste estudo.

0 estudo seguiu os critérios éticos da Resolução 196/96 que ressalva a pesquisa com seres humanos mediante deferimento do Protocolo Ético $n^{\circ}$. (CAAE0141.0.051.000-06), portanto, informados sobre o objetivo da pesquisa e da natureza científica. Após a conclusão da coleta dos dados, estes foram organizados e apreciados, seguindo as análises descritivas, em que foram tabulados e analisados pelo pacote estatístico Statistical Package for the Social Sciences (SPSSWIN), versão 11.0 para a média e o desvio-padrão. Após as análises, os dados foram relacionadas às referências pertinentes à temática proposta.

\section{RESULTADOS E DISCUSSÃO}

Os dados sociodemográficos caracterizam os sujeitos de pesquisa como predominantemente do gênero feminino (90\%), com idades variando entre 25 e 59 anos ( $M=34$ anos), solteiros (53\%), com média de 11 anos de atuação profissional e pertencentes à classe média $(74 \%)$ e alta (26\%). Os resultados indicadores de afetividade estão expressos na Tabela 1. 
Tabela 1: Pontuações médias dos enfermeiros nos indicadores de afetividade. Sousa-PB, 2008.

\begin{tabular}{llllll}
\hline Afetos Positivos & Média & $\begin{array}{c}\text { Desvio- } \\
\text { Padrão }\end{array}$ & Afetos Negativos & Média & $\begin{array}{l}\text { Desvio- } \\
\text { Padrão }\end{array}$ \\
\hline Contente & 6,95 & 1,00 & Preocupado & 2,95 & 0,98 \\
Alegre & 6,89 & 1,04 & Desanimado & 2,00 & 0,87 \\
\hline Animado & 6,79 & 1,03 & Aborrecido & 1,98 & 0,82 \\
Feliz & 5,75 & 1,02 & Impaciente & 1,93 & 0,79 \\
Determinado & 5,66 & 1,01 & Assustado & 1,89 & 0,68 \\
Decidido & 5,55 & 1,01 & Aflito & 1,81 & 0,55 \\
Disposto & 5,59 & 1,00 & Agitado & 1,80 & 0,47 \\
Vigoroso & 5,43 & 0,98 & Envergonhado & 1,78 & 0,42 \\
Dinâmico & 5,32 & 0,95 & Angustiado & 1,68 & 0,32 \\
Entusiasmado & 4,96 & 0,95 & Abatido & 1,59 & 0,24 \\
Seguro & 4,22 & 0,90 & Triste & 152 & 0,19 \\
& & & Deprimido & 1,39 & 0,10 \\
\hline Total & 5,73 & 0,99 & Total & 1,86 & 0,86 \\
\hline
\end{tabular}

Fonte: Pesquisa direta 2008.

Observa-se, no indicador "afetos positivos", que os enfermeiros apresentaram um intervalo variando de 1 a 7 , com média de 5,73 (DP =0,99) e 1,86 (DP =0,86) para os "afetos negativos". Estes resultados sugerem uma congruência do estado de saúde geral dos enfermeiros investigados diante dos indicadores de afetividade e satisfação com a vida no que diz respeito à ansiedade e depressão em seu cotidiano. Dessa forma, percebeu-se que os enfermeiros pesquisados apresentaram afetos positivos significativos, demonstrando que estes se sentem bem, entusiasmados e com prazer no seu cotidiano.

0 afeto positivo representa o quanto uma pessoa sente entusiasmo, energia e prazer pela vida. A ausência de afeto positivo pode ser representada por sintomas como perda de energia e prazer, apatia, cansaço e desesperança. Assim, o afeto negativo representa o quanto uma pessoa pode sentir-se constrangida, desconfortável e insatisfeita, ao invés de sentirse bem. Congrega vários estados aversivos como constrangimento, raiva, culpa, medo, tristeza, desdém, desgosto e preocupação. Estar calmo e relaxado representa ausência de afeto negativo. ${ }^{14}$ Destaca-se que a presença ou a ausência de afetos positivos e/ ou negativos entre enfermeiros têm relação direta e significativa com o bem-estar, com a qualidade de vida e, consequentemente, com a saúde. 0 enfermeiro necessita estar de bem com a vida, pois, de, forma direta, isso causa impactos na sua atuação profissional. Não é possível ter uma boa saúde física sem considerar o emocional. Estudos recentes em relação ao processo saúdedoença comprovam que existe relação entre o fisiológico e 0 psicológico, requisitos para uma pessoa ser considerada saudável bio-psico-sócio-espiritualmente. ${ }^{15}$
No que se diz a respeito à atuação, infere-se que se um enfermeiro for acometido por algum problema de qualquer grau, intensidade, duração e natureza, isso repercutirá no ato de cuidar de outrem. Frequentemente, alterações significativas da afetividade podem afetar o dia a dia dos enfermeiros. Muitas vezes é difícil iniciar o dia, pelo desânimo e pela tristeza ao acordar, o engarrafamento no trânsito, a violência urbana, 0 levar e o buscar os filhos em escolas ou creches, dentre outros rearranjos da vida diária. ${ }^{16}$

Nesse sentido, cuidar das tarefas habituais pode tornarse um peso adicional ao trabalho; dedicar-se a uma outra pessoa e cuidar de filhos podem tornar-se apenas obrigações penosas, ou mesmo impraticáveis, dependendo da gravidade, se as alterações da afetividade evoluem para sintomas mais perceptíveis, tornando, paulatinamente, o relacionamento com outras pessoas mais prejudicado ou intolerável. ${ }^{16}$ Reforça-se que estudo propositivo de análise da saúde geral configura-se como um construto multifatorial, focalizando a afetividade e a subjetividade das relações com os objetos do trabalho do enfermeiro, quer material, quer imaterial, pois encerram fatores de sua realidade laboral que vão além do nexo causal e que podem influenciar a saúde geral e a satisfação em relação à vida.

A saúde não se pode identificar com um estado de normalidade, pois, a nível individual, é um processo único e com manifestações próprias. A saúde não é uma "média", mas uma integração funcional que, individualmente, se alcança por múltiplas e diversas alternativas. ${ }^{17}$

A Tabela 2 apresenta a medida de Satisfação com a Vida, em um intervalo de 1 a 5 , cuja média mostrada pelos enfermeiros foi de 4,03 (DP = 1,32). 


\section{Aproximação à subjetividade de enfermeiros}

Tabela 2: Pontuações médias dos enfermeiros nos indicadores de satisfação com a vida. Sousa-PB, 2008.

\begin{tabular}{lcc}
\hline Satisfação com a vida & Média & $\begin{array}{c}\text { Desvio- } \\
\text { Padrão }\end{array}$ \\
\hline As condições da minha vida são excelentes & 3,99 & 1,30 \\
\hline Estou satisfeito com minha vida & 3,82 & 1,28 \\
Na maioria dos aspectos minha vida é próxima ao meu ideal & 3,75 & 1,22 \\
Dentro do possivel, tenho conseguido as coisas importantes que quero na vida & 3.63 & 1,19 \\
Se pudesse viver uma segunda vez, não mudaria quase nada na minha vida & 2,99 & 1,18 \\
\hline Total & 4,03 & 1,32 \\
\hline
\end{tabular}

Fonte: Pesquisa direta 2008.

Percebeu-se um elevado índice de satisfação com a vida por parte dos enfermeiros deste estudo, por ser extremamente positivo o indicativo de que estes se apresentam com adequado nível de saúde geral, contribuindo, outrossim, com a qualidade de vida e o bem-estar destes profissionais.

A positividade, contudo, não encerra a preocupação e a vulnerabilidade dos profissionais diante das demandas dos processos de trabalho, porém esta deve ser compreendida como um foco que requer medidas de prevenção e promoção dos aspectos qualitativos como garantia de sua saúde geral.

A assistência prestada pela enfermagem visa a atender às necessidades de saúde da sociedade e, como qualquer atividade humana, somente alcançará sua meta se houver condições adequadas. ${ }^{11}$ Assim, a satisfação com a vida não implica que este profissional está livre de preocupações, problemas ou outros sentimentos, tidos como negativos, mas que este profissional encontra-se bem psicologicamente, apesar das adversidades cotidianas vivenciadas no trabalho e na vida pessoal, ou seja, consegue equilibrar os sentimentos negativos e positivos no intuito do bem-estar emocional e consequente qualidade de vida.

0 profissional enfermeiro é um facilitador do crescimento emocional e promotor da saúde, quer sua, quer das demais pessoas sob seus cuidados diretos e indiretos. 0 potencial de saúde centra-se na possibilidade de o enfermeiro encontrar alternativas para a solução de problemas e para conseguir conter os efeitos destrutivos destes, pois assume 0 estatuto social como um profissional competente e hábil diante das demandas da sociedade, nos diversos níveis de atenção e vigilância em saúde, promovendo, protegendo e confortando. Dito de outra forma, responsabilizando-se pela qualidade e estilo de vida daqueles sob seus cuidados.

Considerando a relevância do papel da equipe de enfermagem nos serviços de saúde, muitas das suas atividades possibilitam previsão, organização e administração de recursos para atendimentos de cuidados aos pacientes; assim, é necessário o equilibrio emocional diante das diversas situações que o indivíduo vivencia na sua atuação profissional. ${ }^{11}$

Todavia, vale lembrar que o ser humano não foi "configurado" como uma máquina, podendo despir-se de suas vontades e necessidades. Enquanto ser humano, quão difícil é a missão de cuidar do outro, pois o cuidar enquanto processo, envolve tanto o ser daquele que é cuidado quanto do seu cuidador. $^{2}$

As pessoas que cuidam, sejam elas profissionais ou familiares, sofrem, inevitavelmente, algum tipo de desgaste emocional, principalmente por parte daqueles que se dedicam a esta missão de cuidar de forma mais determinada e responsável possível. 0 que ocorre, muitas vezes, é que acabam por esquecer-se de cuidar também de si mesmas. ${ }^{11}$

Vive-se um momento de efervescência tecnológica e constatação, em que a tecnologia não consegue abranger as necessidades do ser humano. Pesquisas e estudos sobre qualidade de vida (QV) têm crescido significativamente nos últimos anos, mostrando a preocupação dos pesquisadores em suprir o que o avanço tecnológico não foi capaz de realizar. ${ }^{17}$

Usa-se na literatura muitos termos como sinônimos de qualidade de vida, tais como bem-estar, felicidade, boas condições de vida e satisfação na vida. Estudiosos descrivem ou definem o termo qualidade de vida como: sentimento de satisfação com a própria vida em geral; capacidade mental de avaliar sua própria vida como satisfatória; estado aceitável de saúde física, emocional, mental e social; avaliação objetiva procedida por outro que as condições de vida da pessoa são adequadas e não ameaçadoras à vida. ${ }^{18}$ Contudo, ressalte-se que saúde não significa meramente a ausência de doença, mas o completo bemestar físico, psíquico, social e cultural.

\section{CONCLUSÃO}

Os achados deste estudo revelaram que os enfermeiros pesquisados apresentaram afetos positivos expressivos e elevado índice de satisfação com a vida, evidenciando que estes se sentiam bem e demonstravam prazer pela vida, fato significativo para a qualidade de vida e saúde física. Tais resultados são favoráveis no que tange ao exercício profissional, uma vez que o enfermeiro necessita estar bem físico e 
emocionalmente para demonstrar êxito nas diversas situações vivenciadas no ato de cuidar de outrem.

Apesar de os resultados deste estudo serem favoráveis em relação à satisfação e aos afetos dos enfermeiros, cogita-se sobre a existência de sentimentos negativos. Essa indagação conduz à reflexão crítica sobre o assunto, uma vez que, no trabalho em enfermagem, observa-se inúmeras vezes a sobrecarga do enfermeiro e o excesso na jornada de trabalho, o que o distancia do convívio social e familiar, podendo influenciar nos níveis de ansiedade e estresse, estando estes diretamente relacionados à qualidade de vida, ao bem-estar emocional e à saúde física.

Diante da exaustiva carga de trabalho dos enfermeiros, é de suma importância remeter a considerações acerca do "cuidar do cuidador", uma vez que, para cuidar de outrem, é necessário, antes de tudo, que o enfermeiro se sinta bem, e, para isso, precisa também de cuidados. Neste sentido, apresentam-se os seguintes questionamentos: é uma prática fácil o cuidar de si, principalmente, em um ambiente de trabalho excessivo? Considerando o cuidar de si não como uma simples prática, mas como uma habilidade que deve ser estudada e aprimorada desde o processo de formação destes profissionais, as instituições formadoras estão atentas a estas questões? Apresentam tais discussões na sua matriz curricular?

Atualmente, o mercado de trabalho exige cada vez mais destes profissionais, uma vez que devem apresentar um conjunto de conhecimentos técnico-científicos. Urge, portanto, a necessidade de esta categoria conhecer com maestria, ter equilibrio entre a razão e a emoção, deter habilidades e atitudes relacionais, receber formação, desde a graduação, considerando os aspectos subjetivos do ser, que considere, enfim, a sua capacidade enquanto profissional da saúde, desenvolvendo ações de prevenção e promoção da saúde, não somente com os usuários do serviço, mas principalmente com ele mesmo, pois quem produz o cuidado deve primordialmente se cuidar.

\section{REFERÊNCIAS}

1.Roy C, Andrews HA. Teoria de enfermagem: o modelo de adaptação de

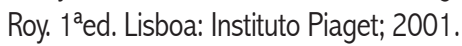

2. Remen RN. O paciente como ser humano. Tradução de Denise Bolanho. São Paulo: Summus; 1993.

3. Borsoi ICF, Codo W. Sofrimento psíquico nas organizações: saúde mental e trabalho. In: Enfermagem, trabalho e cuidado. Petrópolis: Vozes; 1995. p.39-151.

4. Silva J. Consumo de pesquisa, saúde intelectual e retorno social em reflexão sobre a prática de enfermagem [Editorial]. Esc Anna Nery. 2008; 12(3): 403-5.

5. Dalgalarrondo P. Psicopatologia e semiologia dos transtornos mentais. Porto Alegre: Artmed; 2000.
6. Carvalho V. Sobre a objetividade na relação sujeito-objeto no plano da imagem ou da esfera instrumental/organizacional: um ponto de vista para a pesquisa na enfermagem. Esc Anna Nery. 2008; 12(2):334-40.

7. Boff L. Saber cuidar: ética do humano - compaixão pela terra. Petrópolis, RJ: Vozes; 1999.

8. Waldow VR. Cuidado Humano: o resgate necessário. Porto Alegre: Sagra Luzatto; 1998.

9. Espedirão $E$, Munari DB. Repensando a formação do enfermeiro e investindo na pessoa: algumas contribuições da abordagem gestáltica. Rev Bras Enferm. 2000; 53(3):339-40.

10. Gonzalez-Rey F. Pesquisa qualitativa e subjetividade: os processos de construção da informação Tradução de Marcel Aristides Ferrada Silva. São Paulo: Pioneira Thomson Learning; 2005

11. Fernandes MV, BatistaAS, Leite MAN. Endomarketing: uma possibilidade nos serviços de saúde. [Internet] 2002; [citado 2006 dez 5]. Disponível em: http://www.ccs.uel.br/espaçoparasaude/v3n2/doc/endomarketing.

12. Borges LO, Argolo JCT. Adaptação e validação de uma escala de bemestar psicológico para uso em estudos ocupacionais. Aval Psicol. 2002; $1(1): 17-27$.

13. Gouveia W, Chaves SSS, Oliveira ICP. The use of the GHQ-12 in a general population: a study of its construct validity. Psicol Teor Pesqui. 2003; 19(3): 241-8.

14. Andrade HSG, Gorenstein C. Aspectos gerais das escalas de avaliação de ansiedade. Rev Psq Clin. [Periódico na internet]. 1998; [Citado 2003 nov 15]; 25(6). Edição Especial. Disponivel em: http://www.hcnet.usp.br/ ipq/revista/r256/ansi256a.htm

15. Breilh J, Granda E. Investigação da saúde na sociedade: guia pedagógico sobre um novo enfoque do método epidemiológico. São Paulo: Cortez/ABRASCO; 1991. 115p.

16. Gonzalez-Rey F. Psicologia e saúde: desafios atuais. Psicol Reflex Crit. 1997; 10(2):275-88.

17. Lentz RA, Costenaro RGS, Gonçalves LHT, Nassar SN. O profissional de enfermagem e a qualidade de vida: uma abordagem fundamentada nas dimensões propostas por Flanagan. Rev Latino-am Enfermagem. 2000; $8(4): 7-14$.

18. Meeberg GA. Quality of life: a concept analysis. J Adv Nurs. 1993; 18(23):32-8. 